\title{
Bilateral Mediastinal Bronchogenic Cysts - A Case Report
}

Nanda Patil ${ }^{1}$, Parneet Kaur ${ }^{2 *}$, Supriya Karmakar ${ }^{2}$, Snigdha Vartak ${ }^{2}$

${ }^{1}$ Professor, Department of Pathology, Krishna Institute of Medical Sciences Deemed to be University, Karad, India

${ }^{2}$ Tutor, Department of Pathology, Krishna Institute of Medical Sciences Deemed to be University, Karad, India

DOI: $10.36347 /$ sjams.2020.v08i07.008

| Received: 29.06.2020 | Accepted: 06.07.2020 | Published: 09.07.2020

*Corresponding author: Dr. Parneet Kaur

Abstract

Bronchogenic cyst is one of the broncho-pulmonary anomaly which is very rare. These cysts are mostly situated in the mediastinum near the carina and rarely within the lung parenchyma, pleura or diaphragm. Most are found incidentally and symptoms are related to compression of the trachea, bronchi or esophagus. We report a rare case of bilateral mediastinal bronchogenic cysts in a 19 weeks male abortus.

Keywords: Bronchogenic cyst, Mediastinum, Foregut, Duplication cyst.

Copyright @ 2020: This is an open-access article distributed under the terms of the Creative Commons Attribution license which permits unrestricted use, distribution, and reproduction in any medium for non-commercial use (NonCommercial, or CC-BY-NC) provided the original author and source are credited.

\section{INTRODUCTION}

Bronchogenic cyst is a rare type of bronchopulmonary anomaly, the prevalence of which is $5-10 \%$ of pediatric mediastinal masses [1].

Bronchogenic cysts are congenital malformation resulting as a part of the spectrum of foregut duplication cyst. They form as a result of abnormal ventral budding of the tracheobronchial tree [2]. When they are formed early the common site is anterior mediastinum close to trachea and esophagus or carina and main bronchi, but they do not communicate with the tracheobronchial tree. When they occur in the later life during bronchial budding and branching, these cysts are found within the lung [3, 4].

We present a rare case of bilateral bronchogenic cyst in a 19 weeks male abortus.

\section{Case Report}

A 23 years old primigravida female patient visited ANC OPD in our institute. The ultrasonography at 19 weeks of gestation revealed cystic malformations in the thoracic cavity. Medical abortion was performed and the abortus was sent for autopsy.

ANC history of mother revealed consanginous marriage, other ANC investigations were normal. Autopsy was performed in 19 weeks male abortus.

External examination of the male abortus did not reveal significant findings. After dissection, thoracic cavity revealed two large cystic structures on right and left side of mediastinum anteriorly. The larger one measuring $4.3 \mathrm{~cm}$ and smaller one measuring $3.2 \mathrm{~cm}$ in diameter. On opening both cysts were unilocular and revealed serous fluid.Both cysts revealed no communication with trachea or bronchus (Fig 1, 2 and 3).

Abdominal cavity and cranial cavity did not reveal significant findings. Microscopy of the cyst revealed lining by ciliated epithelium and the wall of the cyst showed smooth muscle mixed with few glands and cartilage tissue. (Figure 4, 5 and 6) Gross and microscopic features of all other organs revealed signs of prematurity and no specific findings.

\section{DiSCUSSION}

Bronchogenic cysts are most commonly seen in the mediastinum typically near the carina. Less commonly they are found within the lung tissue, pleura or diaphragm [5].

They can be seen over a wide age range from infants to adults [6]. Frequently these cysts are solitary and associated malformations are rare [7]. Our case revealed bronchogenic cyst in anterior mediastinum on right and left side with no other congenital malformations.

Most bronchogenic cysts remain asymptomatic when the size is smaller. Symptoms are generally caused by compression of the trachea, bronchi and esophagus presenting as stridor, dyspnea and dysphagia. They can threaten life by infection, hemorrhage and rupture [6]. 
Microscopy of these cysts reveals ciliated columnar lining with a fibrous wall containing cartilage and bronchial glands [8]. Similar observation was seen in our case. Differential diagnoses of bronchogenic cyst include adenomatoid malformation of lung, neuroenteric cyst, esophageal duplication cyst, cystic hygromas and congenital diaphragmatic hernias [9-11].

Esophageal duplication cysts are located in middle or posterior mediastinum. Also neuroenteric cysts are observed in posterior mediastinum and are frequently associated with vertebral defects [12].
Diagnosis of bronchogenic cyst is done with radiological investigations like ultrasonography and CT scan of thorax. Symptomatic cysts require surgical resection.

\section{CONCLUSION}

Bronchogenic cysts are rare congenital malformations. Early diagnosis in antenatal period is necessary for appropriate guidance of the clinicians.

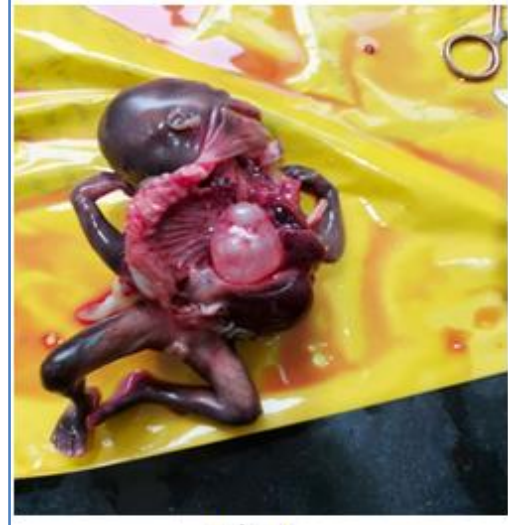

Fig-1

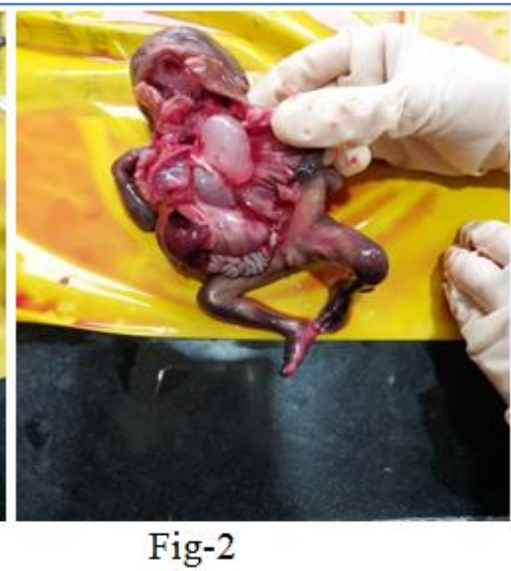

Fig-1and 2: Thoracic cavity showing large unilocular cysts in anterior mediastinum on right and left side

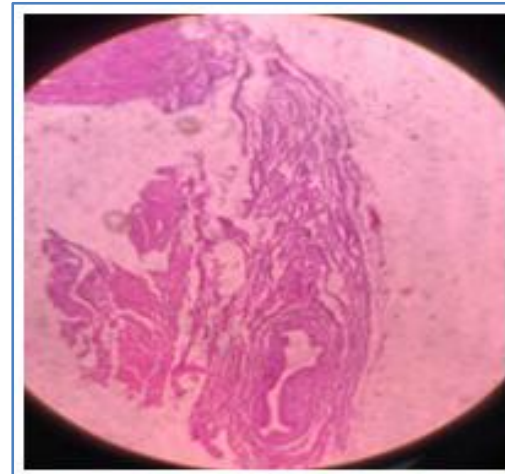

Fig-3

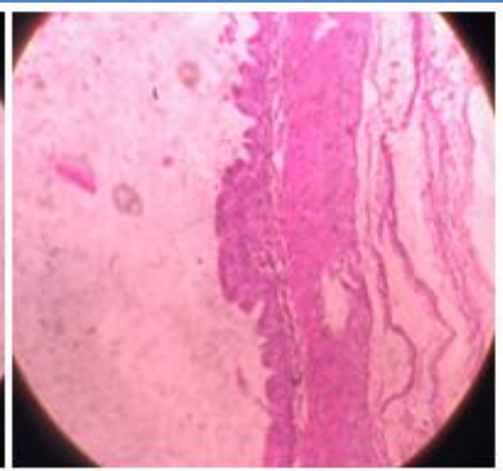

Fig-4

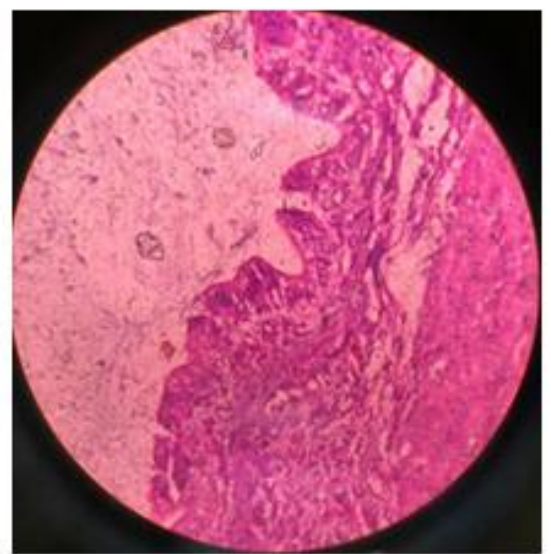

Fig-5

Fig-3, 4 and 5 - Microscopy of cyst, lined by ciliated columnar epithelium, one showing muscle tissue and bronchial glands 


\section{REFERENCES}

1. Biyyam DR, Chapman T, Ferguson MR, Deutsch G, Dighe MK. Congenital lung abnormalities: Embryologic features, prenatal diagnosis, and postnatal radiologic-pathologic correlation. www.rsna.org/education/rg_cme.html

2. Pare JAP, Fraser RG. Synopsis of diseases of chest. Philadelphia, Pa: Saunders. 1983.

3. Shamji FM, Sachs HJ, Perkins DG. Cystic disease of the lung. Surg Clin North Am. 1988; 68:581620.

4. St. Georges R, Deslauriers J, Duranceau A. Clinical spectrum of bronchogenic cysts of the mediastinum and lung in the adult. Ann Thorac Surg. 1991; 52:6-13.

5. McAdams HP, Kirejczyk WM, Rosado-deChristenson ML, and Matsumoto S. Bronchogenic cyst: imaging features with clinical and histopathologic correlation. Radiology. 2000; 217(2): 441-446
6. Ribet M, Copin MC, Gosselin BH. Bronchogenic cysts of the lung. Ann Thorac Surg. 1996; 61:163640.

7. Jaggers J, Balsara K. Mediastinal Masses in Children. Thoracic and Cardiovascular Surgery. 2004; 16:201-208.

8. Sayler DC, Salyer WR, Eggleston JC. Benign developmental cysts of the mediastinum. Arch Pathol Lab Med. 1977; 101:136-139.

9. Langston C. New concepts in the pathology of congenital lung malformations. Semin Pediatr Surg. 2003; 12(1):17-37.

10. Newman JP, Crues JV, Vinstein AL, Medearis AL. Sonographic diagnosis of thoracic gastroenteric cyst in utero Prenat Diagn. 1984; 4:467.

11. Graham D, Winn K, Dex W, Sanders RC. Prenatal diagnosis of cystic adenomatoid malformations of the lung J Ultrasound Med. 1982; 1:9-12.

12. Patil N, Kanetkar S, Mane A, Patel G, Salahudeen A. Thoracic neuroenteric cyst arising in posterior mediastinum in a premature male infant $-\mathrm{A}$ case report. SJMCR. 2019; 7:88-90. 